\title{
PAPAN GEKOLA SEBAGAI MEDIA PEMBELAJARAN MATEMATIKA YANG INOVATIF DENGAN PENDEKATAN STEAM
}

\section{GEKOLA BOARD FOR INOVATIF MATH LEARNING MEDIA WITH STEAM APPROACH}

\author{
Noni Dwi Sari ${ }^{1 *}$, dan Jan Setiawan ${ }^{2)}$ \\ 1) Sekolah Menengah Pertama Insan Rabbanu, Jl. Ciater Raya Sektor 1.1 Bumi Serpong Damai, Kota \\ Tangerang Selatan, Banten \\ *nonidwisari@gmail.com \\ 2) Program Studi Teknik Elektro, Fakultas Teknik, Universitas Pamulang, Jl. Raya Puspiptek, Buaran, \\ Kota Tangerang Selatan, Banten
}

\begin{abstract}
Innovative and creative learning through interdisciplinary must be done to overcome technological developments in the 21 century and the industrial revolution 4.0. The use of teaching media is essential to make education in mathematics more dynamic and to meet the challenges of the time. For this reason, the author tries to develop learning media Geometry, Coordinates and Patterns (GEKOLA BOARD), which have been developed using the STEAM approach to create innovative, fun and meaningful interdisciplinary learning. This research is a classroom action research (CAR) conducted at the Insan Rabbany Junior High School. The subject of this research is class VII students, and this research was carried out in 2 cycles with research data collection in the form of documentation, interviews and using survey research instruments. The results showed that increases the achievement of effectiveness on learning. The increases on aspect value at the end of the second cycle the activity aspect showed an average value at 89.5, the creation and innovation aspect showed an average value at 90, and analytical skills aspect showed an average value at 91. The overall learning effectiveness showed an exceptional results. That indicates that using the Gekola board with the STEAM approach was a practical learning innovation to meet the challenges of the industrial revolution 4.0, since interdisciplinary learning, which is required for students, is successfully implemented.
\end{abstract}

Keywords: Gekola Board, Quadrilateral, STEAM.

\begin{abstract}
ABSTRAK
Seiring dengan perkembangan teknologi abad 21 dan untuk menghadapi revolusi industri 4.0 penyelengaran pembelajaran diharapkan lebih inovatif dan kreatif berupa pembelajaran lintas disiplin ilmu. Penggunaan media pembelajaran dalam prosesnya memang mutlak dilakukan agar pembelajaran matematika lebih dinamis dan mampu menjawab tantangan zaman. Untuk itulah penulis mencoba mengembangkan media pembelajaran Papan Geometri, Koordinat dan Pola (papan Gekola) yang dalam penggunaannya dikembangkan dengan pendekatan STEAM sehingga tercipta pembelajaran lintas disiplin ilmu yang inovatif dan menyenangkan serta bermakna. Dengan penelitian tindakan kelas (PTK) dua siklus yang dilaksanakan di SMP Insan Rabbany. Subjeknya adalah siswa kelas 7. Instrumen data berupa foto dokumentasi,
\end{abstract}


wawancara dan survey. Hasil pengembangan media papan Gekola dengan model pembelajaran pendekatan STEAM materi bangun datar menunjukkan peningkatkan efektivitas pembelajaran ditinjau dari aspek keaktifan yang memiliki nilai rata rata 89,5, aspek kreasi dan inovasi dengan nilai rata rata 90 serta aspek kemampuan analisis dengan nilai rata rata 91 pada akhir siklus kedua. Secara keseluruhan efektifitas pembelajaran menunjukkan hasil yang sangat baik. Hal ini menunjukkan penggunaan media papan Gekola dengan pendekatan STEAM merupakan suatu inovasi pembelajaran yang efektif untuk menghadapi tantangan revolusi industry 4.0 karena berhasil menerapkan pembelajaran lintas disiplin ilmu yang diperlukan bagi siswa

Kata kunci: Papan Gekola, Bangun Datar, STEAM.

\section{PENDAHULUAN}

Matematika sebagai salah satu pelajaran yang mengasah konsep dan pola pikir siswa diharapkan bukan lagi menjadi momok yang menakutkan bagi siswa. Untuk itu diperlukan proses pembelajaran matematika yang menyenangkan, inovatif dan bisa diimplementasikan dalam kehidupan agar motivasi dan minat siswa pada pembelajaran matematika bisa meningkat. Sejalan dengan hal tersebut pembelajaran dengan pendekatan Science Technology Engineering Mathematics (STEM) merupakan pendekatan dalam proses pembelajaran yang mengkombinasikan sains, teknologi, teknik, matematika, dan seni dalam proses pembelajaran. Pembelajaran dapat didefinisikan sebagai kemampuan yang dimiliki peserta didik setelah memperoleh pengalaman melakukan aktivitas (Hamalik, 2007). Pembelajaran dengan pendekatan STEM bertujuan agar siswa dapat lebih mudah memahami konsep yang akan disampaikan dan dapat menerapkannya dalam kehidupan sehari-hari serta dapat menggali potensi yang ada dalam dirinya. Pengembangan selanjutnya yakni dengan penambahan "Art" menjadi STEAM untuk lebih mengeksplorasi kreativitas dan seni siswa. Menurut Henriksen (2014) pembelajaran STEAM selain memperkuat pembelajaran siswa pada seluruh disiplin ilmu, juga melalui disiplin ilmu tersebut siswa mendapatkan kesempatan untuk mengeksplorasi dan membuat hubungan antara seni, musik, sains, dan lain-lain. Selain itu dengan STEAM siswa merasa lebih termotivasi dan lebih efektif dalam belajar. Menurut Wijaya, et al (2015) pembelajaran STEM dibutuhkan oleh siswa-siswi Indonesia sebagai upaya untuk melatih kemampuan dan bakat mereka untuk menghadapi masalah abad 21. Berdasarkan hasil laporan Onner dkk (2016) menunjukkan hasil penelitian yang bertujuan untuk melihat tingkat kepercayaan diri siswa yang melakukan pembelajaran dengan STEM yang dikombinasikan dengan seni. Hasilnya terdapat peningkatan kepercayaan diri siswa setelah melaksanakan pembelajaran dengan STEM dan seni yang diistilahkan kedalam 
STEAM. Metode Claudia Cornett's With About In and Through (WAIT) saat mendesain pembelajaran STEAM mampu meningkatkan pencapaian belajar siswa (Kuhn, 2015).

Media dalam proses pembelajaran merujuk pada perantara atau pengantar sumber pesan dengan penerima pesan, merangsang pikiran, perasaan, perhatian dan kemauan sehingga terdorong serta terlibat dalam pembelajaran (Nurhidayati, 2017). Adanya penggunaan media pembelajaran dalam proses pembelajaran dan kebutuhan akan pembelajaran lintas disiplin ilmu memang mutlak dilakukan agar pembelajaran matematika bisa lebih inovatif, dinamis dan mampu menjawab tantangan zaman. Dalam upaya mencapai hasil pembelajaran yang baik guru seharusnya mampu menggabungkan antara aktivitas yang diarahkan orang dewasa atau guru dalam bentuk perencanaan pembelajaran, dengan dan aktivitas yang diarahkan oleh anak atau siswa dalam bentuk permainan yang disenanginya (Brooker, 2017). Untuk itulah penulis mencoba mengembangkan suatu media pembelajaran Papan Geometri, Koordinat dan Pola yang selanjutnya penulis sebut sebagai papan GEKOLA yang dalam penggunaannya dikembangkan dengan model pembelajaran STEAM sehingga tercipta suatu pembelajaran lintas disiplin ilmu yang tidak hanya inovatif dan menyenangkan namun juga bermakna.

\section{METODOLOGI}

Penelitian yang dilakukan berupa penelitian tindakan kelas (PTK) dengan subjek penelitian ini adalah siswa kelas VII di SMP Insan Rabbany sebanyak 52 siswa, dan penelitian ini dilaksanakan pada tahun ajaran 2018 - 2019 yakni dibulan Februari - Maret 2019. Instrumen penelitian menggunakan dokumentasi dari kegiatan observasi, wawancara dan kuisioner selama proses pembelajaran berlangsung.

Uji validitas didapatkan dari pemberian kuisioner kepada 10 rekan sejawat penulis yang juga mengajar matematika. Skor persentase validitas didapat dari hasil penilaian validator terhadap 15 indikator kriteria yang berasal dari dua aspek validasi yaitu aspek yang berhubungan dengan penggunaan media papan Gekola pada materi bangun datar dan aspek yang berhubungan dengan model pembelajaran pendekatan STEAM. Setiap indikator dinilai menggunakan skor 1 sampai 5. Riduwan (2015:53) mengasumsikan bahwa skor 1 bermakna buruk sekali, skor 2 bermakna buruk, skor 3 bermakna sedang, skor 4 bermakna baik dan skor terakhir 5 bermakna baik sekali. Sedangkan hasil skor persentase diasumsikan bahwa persentase respon $\leq 25 \%-40 \%$ 
dinyatakan tidak valid, $41 \%$ - 55\% dinyatakan kurang valid, 56\% - 70\% dinyatakan cukup valid, $71 \%$ - 85\% dinyatakan valid, dan $86 \%-100 \%$ dinyatakan sangat valid.

Untuk uji efektivitas dilihat dari hasil penilaian produk dan hasil penilaian selama proses pembelajaran siswa. Aspek yang dinilai selama pembelajaran berlangsung yakni aspek keaktifan, aspek kreasi dan inovasi serta aspek analisis. Penelitian ini dilaksanakan dalam 2 siklus dimana kegiatan tahapan yang dilakukan dijelaskan dalam Tabel 1.

Tabel 1. Tahapan penelitian

\begin{tabular}{|c|l|}
\hline Siklus & \multicolumn{1}{|c|}{ Tahap } \\
\hline 1 & Perencanaan \\
& Pelaksanaan siklus 1 \\
& Observasi \\
& Refleksi \\
\hline 2 & Perencanaan \\
& $\begin{array}{l}\text { Pelaksanaan siklus 2 } \\
\text { Observasi } \\
\\
\text { Refleksi }\end{array}$ \\
\hline
\end{tabular}

Fokus tindakan pada tahap 1 meliputi kegiatan penyusunan RPP, perancangan kegiatan, penyusunan rubrik penilaian proyek dan wawancara serta dokumentasi. Fokus tindakan pada tahap 2 meliputi penyusunan RPP, Perancangan kegiatan setelah refleksi siklus 1, Penyusunan Rubrik penilaian proyek, Penyusunan kuisioner, dokumentasi.

Pembelajaran yang diterapkan ialah melalui beberapa tahapan dengan menggunakan Engineering Design Process (EDP). Engineering design process $(E D P)$ yang didefinisikan sebagai serangkaian langkah-langkah yang menggunakan teknik untuk membimbing mereka dalam memecahkan masalah yang diberikan. Adapun siklus EDP dirangkum dalam Gambar 1.

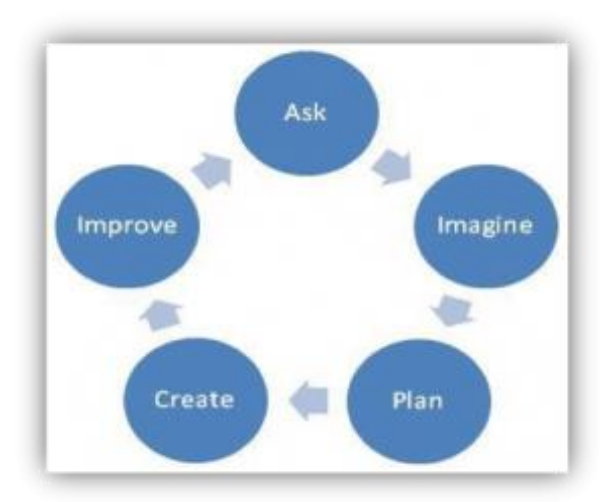

Gambar 1. Siklus EDP 
Pembelajaran merupakan proses komunikasi dan berlangsung dalam suatu sistem. Media pembelajaran menjadi salah satu komponen yang penting dalam sistem pembelajaran (Daryanto, 2012). Langkah langkah pembelajaran matematika dengan model pendekatan STEAM disusun dengan berbasis proyek yakni dengan membuat 2 tahapan proyek yang saling berkesinambungan untuk merangsang pola pikir dan daya imajinasi siswa untuk meningkatkan efektivitas pembelajaran.

Tahap I adalah proses perancangan bangun datar, pada tahap ini siswa diajak berpikir kritis dan bekerja sama untuk bisa membuat bangun datar sebanyak dan seluas mungkin dengan analisis biaya optimal.

Tahap II dalam pengerjaan proyek, pada tahap ini siswa diminta untuk merancang terlebih dahulu kombinasi bangun datar yang telah mereka buat pada selembar kertas kotak kotak atau millimeter blok untuk disusun membentuk suatu gambar atau lukisan, kemudian dengan menggunakan papan Gekola dibentuk model bangun datar yang sudah direncanakan yang selanjutnya pembuatan cetakan kombinasi bangun datar menggunakan media cetak adonan bunga sabun.

\section{PEMBAHASAN}

Data hasil aplikasi praktis pengembangan media pembelajaran papan Gekola dengan model pembelajaran pendekatan STEAM yang dilakukan menggunakan metode penelitian tindakan kelas dengan kegiatan dilakukan dengan 2 siklus. Data yang diambil berasal dari kegiatan observasi, wawancara dan kuisioner selama proses pembelajaran berlangsung untuk mengetahui efektivitas pembelajaran yang dilihat dari hasil penilaian produk dan hasil penilaian selama proses pembelajaran siswa. 


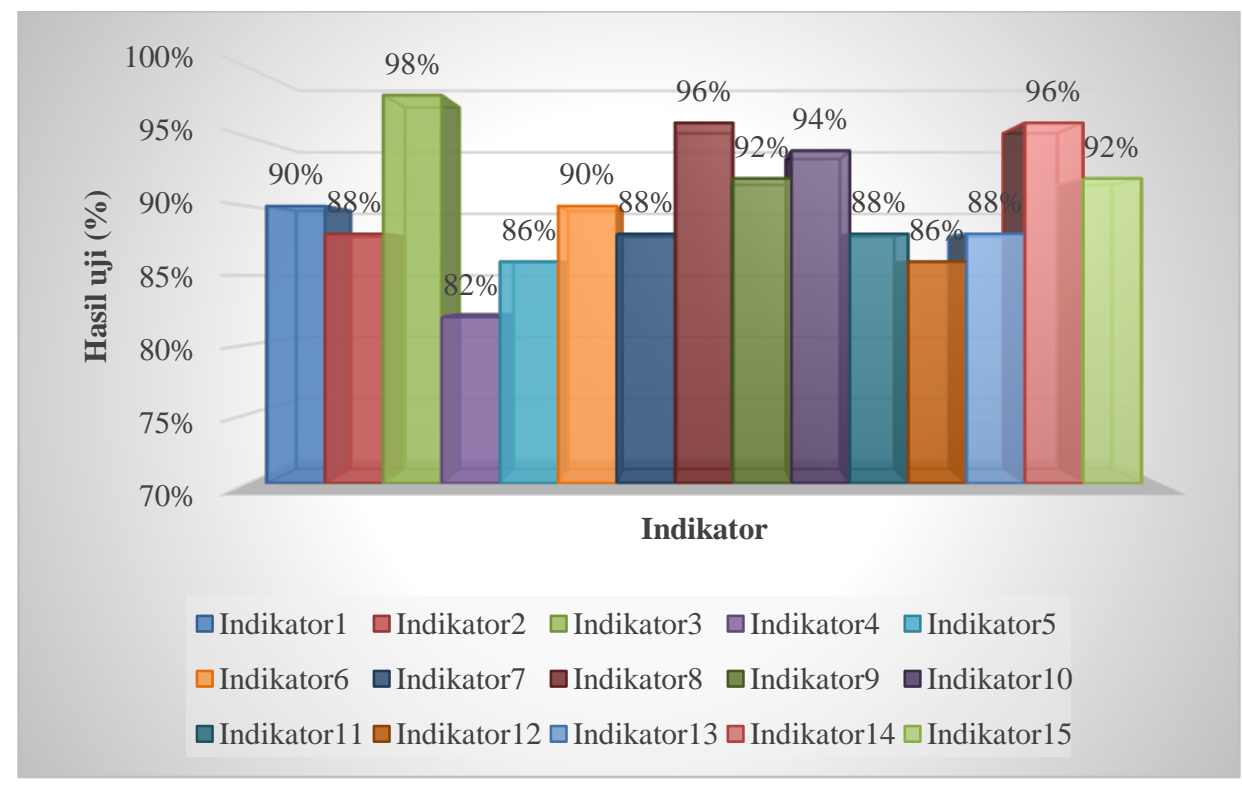

Gambar 2. Diagram Batang Hasil Uji Validitas

Uji validitas didapatkan dari pemberian kuisioner kepada 10 rekan sejawat penulis yang juga mengajar matematika. Hasil dari pengujian vailiditas disajikan pada Gambar 2. Skor persentase validitas didapat dari hasil penilaian validator terhadap 15 indikator kriteria yang berasal dari dua aspek validasi yaitu aspek yang berhubungan dengan materi dan aspek yang berhubungan dengan kinerja media pembelajaran. Setiap indikator dinilai menggunakan skor 1 sampai 5. Ridwan (2015:53) mengasumsikan bahwa skor 1 bermakna buruk sekali, skor 2 bermakna buruk, skor 3 bermakna sedang, skor 4 bermakna baik dan skor terakhir 5 bermakna baik sekali. Sedangkan hasil skor persentase diasumsikan bahwa persentase respon $\leq 25 \%-40 \%$ dinyatakan tidak valid, $41 \%-55 \%$ dinyatakan kurang valid, $56 \%-70 \%$ dinyatakan cukup valid, $71 \%$ - $85 \%$ dinyatakan valid, dan $86 \%-100 \%$ dinyatakan sangat valid.

Sedangkan hasil uji efektivitas pembelajaran diperoleh melalui hasil penilaian produk dan penilaian proses selama pembelajaran berlangsung. Aspek yang dinilai selama pembelajaran berlangsung yakni aspek keaktifan yang ditinjau dari keseriusan mendengar penjelasana guru, keaktifan dalam berdiskusi, sikap dalam proses merancang produk dan sikap apresiasi peserta didik terhadap peserta didik lain. Aspek kreasi dan inovasi penulis kaji dari kemampuan merancang bangun datar, kerja sama dalam menciptakan produk, keaslian produk yang dihasilkan dan komposisi dan proporsi bangun datar yang dihasilkan serta aspek analisis yang dikaji dari kemampuan 
menginterprestasikan instruksi, kemampuan analisis luas bangun datar, kemampuan membuat media cetak bunga sabun, dan kemampuan menyelesaikan karya yang dilakukan pada siklus 1 dan siklus 2 .

Dari hasil pengamatan mengenai keaktifan siswa selama pembelajaran menggunakan media papan Gekola dengan pembelajaran STEAM dapat dillihat dari rata-rata nilai pada Gambar 3,

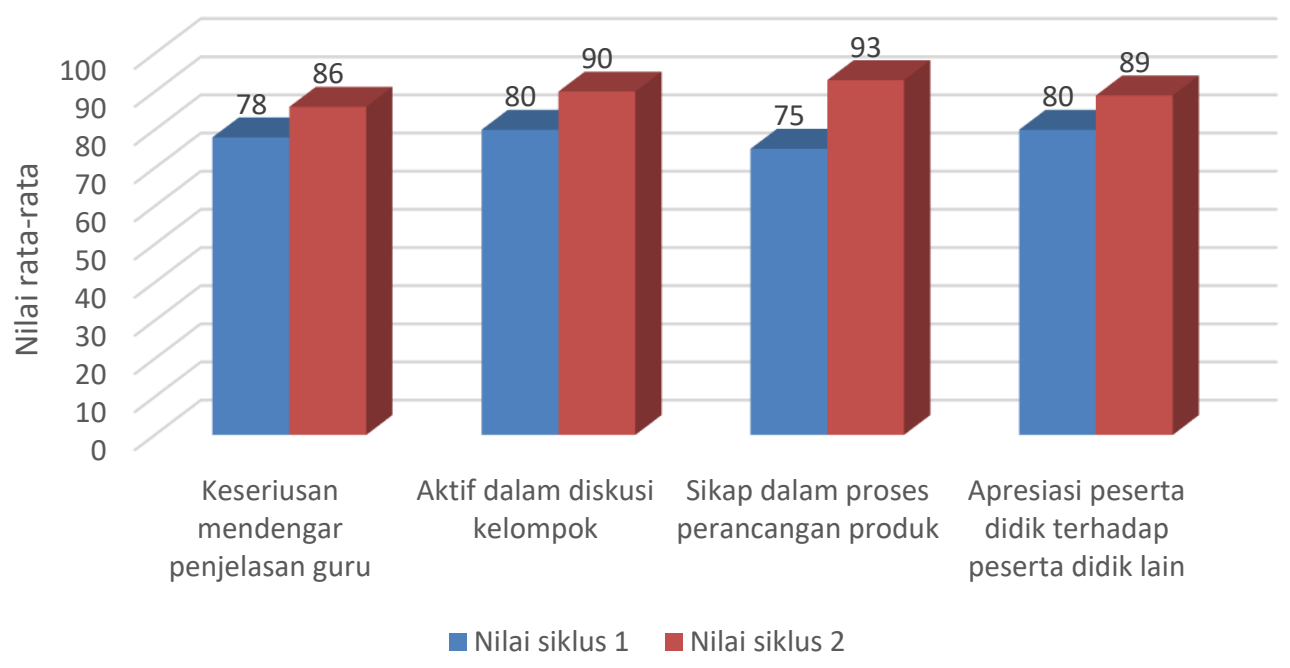

Gambar 3. Grafik hasil pengamatan aspek keaktifan.

Pada grafik terlihat nilai keaktifan dalam berdiskusi dan apresiasi peserta didik terhadap peserta didik lain memiliki nilai tertinggi yang sama yakni 80 pada siklus satu yang menunjukkan bahwa peserta sudah aktif dalam berdiskusi dan mengapresiasi peserta didik lain, sedangkan pada siklus dua terlihat nilai tertinggi pada sikap dalam proses perancangan produksi, hal ini menunjukkan peserta didik mengalami peningkatan dalam kemampuan pada proses perancangan produksi yakni membuat bentuk gambar yang bernilai seni menggunakan bangun datar dengan media papan Gekola.

Untuk hasil pengamatan mengenai kreasi dan inovasi siswa selama pembelajaran menggunakan media papan Gekola dengan model pembelajaran STEAM dapat dillihat dari rata-rata nilai pada Gambar 4. 


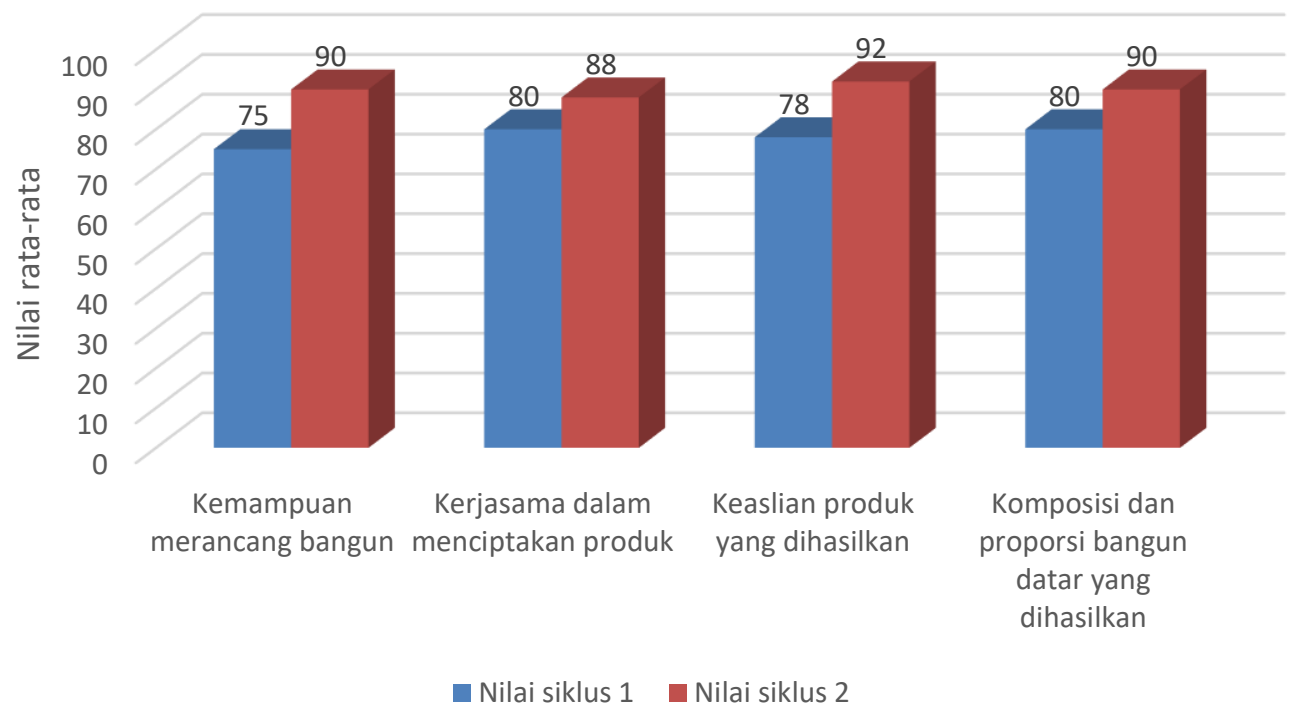

Gambar 4. Grafik hasil pengamatan aspek kreasi dan inovasi

Pada pengamatan aspek kreasi dan inovasi peningkatan tertinggi diperoleh dari keaslian produk yang dihasilkan yang menunjukkan bahwa siswa berusaha menggunakan kreasi dan inovasi yang dimilikinya untuk mendapatkan bentuk lukisan bangun datar yang bernilai seni.

Dari hasil pengamatan mengenai kemampuan analisis siswa selama pembelajaran menggunakan media papan Gekola dengan pembelajaran dapat dillihat dari rata-rata nilai pada Gambar 5.

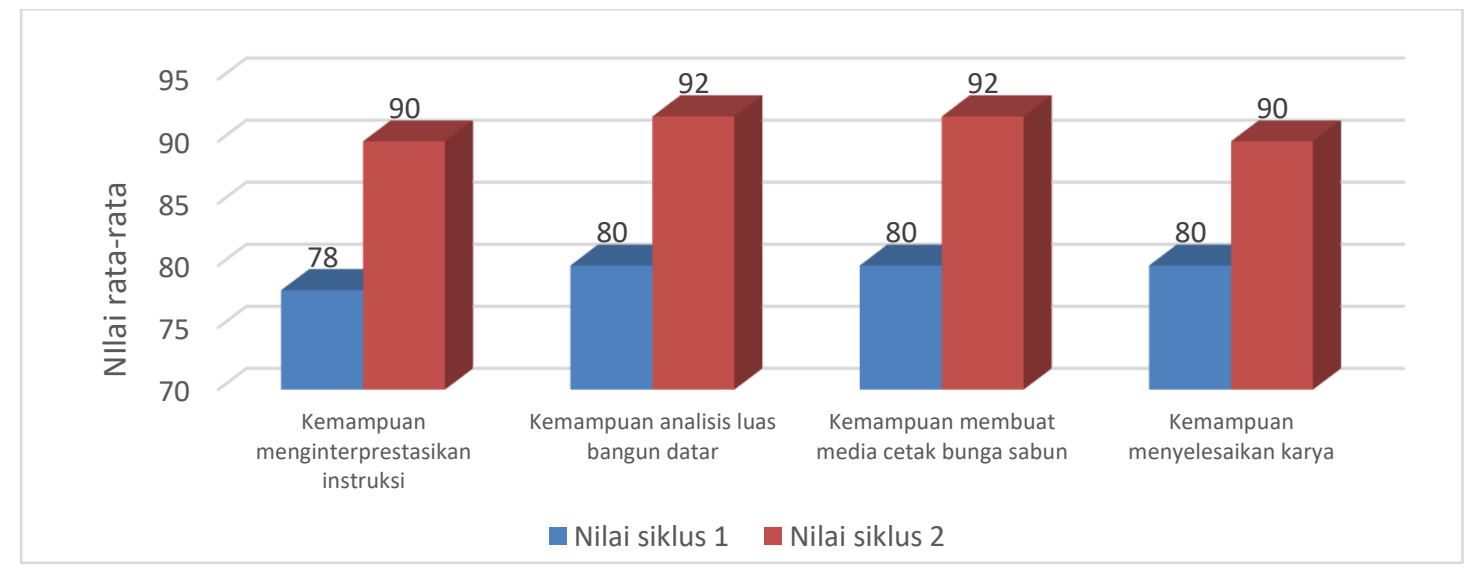

Gambar 5. Grafik hasil pengamatan aspek kemampuan analisa 
Pada grafik diatas terlihat kemampuan analisis luas bangun datar dan membuat media cetak bunga sabun memperoleh nilai tinggi. Hal ini menunjukkan peserta didik dapat mengembangkan daya Analisa yang dimilikinya untuk menganalisis luas bangun datar yang telah digunakan dan juga membuat media cetak bunga sabun.

Analisis Hasil Implementasi Praktis Pengembangan Media Pembelajaran Papan Gekola dengan pembelajaran STEAM berdasarkan hasil uji validitas secara keseluruhan sebesar $90 \%$. Angka ini berada di atas $85 \%$ yang menunjukkan bahwa media pembelajaran papan Gekola dengan model pembelajaran STEAM valid untuk digunakan. Demikian pula berdasarkan hasil wawancara dengan rekan sejawat yang pada umumnya menyatakan bahwa media pembelajaran papan Gekola dengan model pembelajaran STEM mudah untuk diimplementasikan. Selanjutnya pada rekapitulasi efektivitas pembelajaran dari tiap-tiap aspek yang dikaji terlihat pada Gambar 13:

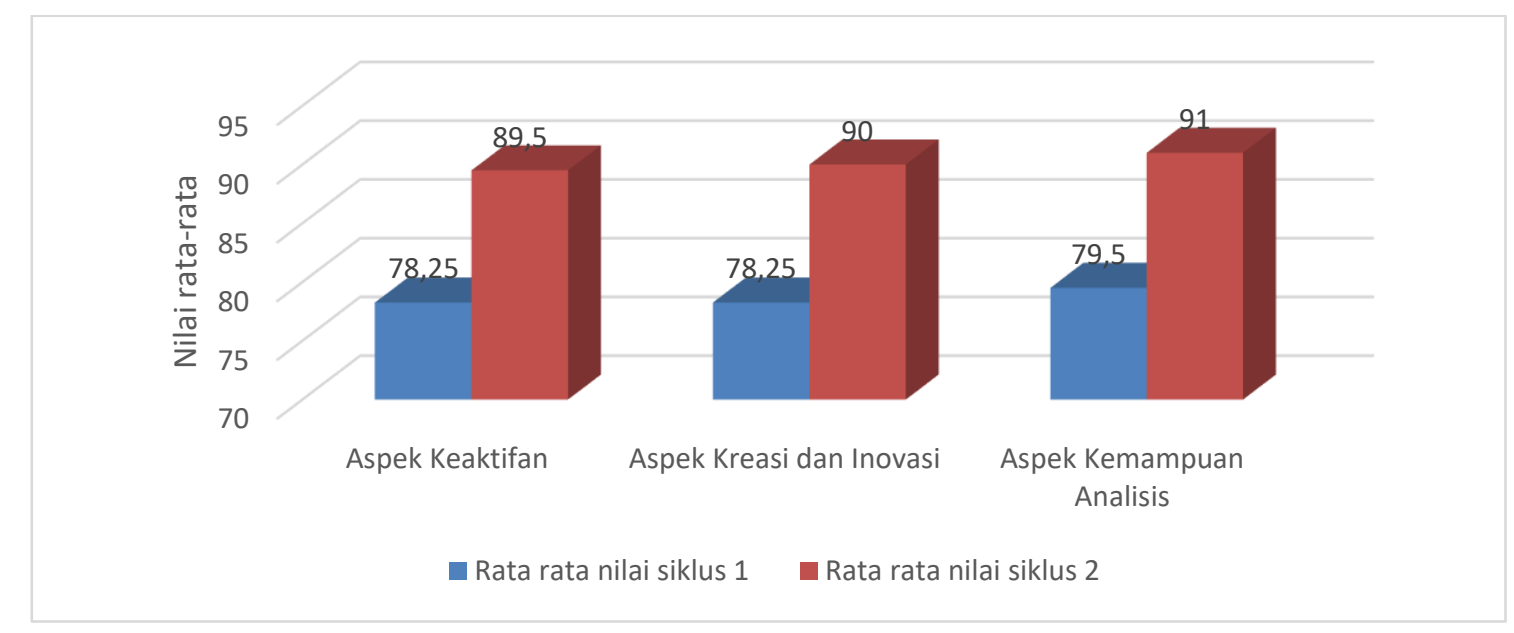

Gambar 13. Grafik rekapitulasi efektivitas pembelajaran

Berdasarkan hasil uji efektivitas pembelajaran pada siklus 1 dan 2 menunjukkan bahwa pengembangan media papan Gekola dengan model pembelajaran STEAM meningkatkan efektivitas belajar (Ismayani, 2016) bagi siswa untuk materi bangun datar dengan nilai teringgi pada kemampuan analisis siswa dalam menghitung luas bangun datar dan proses pembuatan cetakan bunga sabun. Penggunaan media papan Gekola dengan model pembelajaran STEAM dalam pembelajaran materi bangun datar dapat dikatakan tepat, dimana dapat menumbuhkan rasa senang siswa terhadap pelajaran (Ferdian, 2013). Penggunaan media papan sangat membantu siswa lebih mudah memahami materi yang 
dipelajari dan guru lebih mudah dalam mengajar (Takahashi, 2002: Mayasari, 2017 : Keraf, 2017).

\section{SIMPULAN}

Hasil kajian pengembangan media papan Gekola dengan pembelajaran STEAM dapat disimpulkan bahwa :

1. Media pembelajaran papan Gekola dengan model pembelajaran STEAM dapat meningkatkan efektivitas pembelajaran dengan nilai rata rata pada akhir siklus 2 yakni dari aspek keaktifan yang memiliki nilai rata rata 89,5, aspek kreasi dan inovasi dengan nilai rata rata 90 serta aspek kemampuan analisis dengan nilai rata rata 91. Secara keseluruhan menunjukkan hasil yang sangat baik.

2. Media pembelajaran papan Gekola dengan pembelajaran STEM memiliki tingkat validitas yang valid yatu sebesar $90 \%$, dan berdasarkan hasil wawancara dengan rekan sejawat menunjukkan bahwa media pembelajaran papan Gekola dengan pembelajaran STEM mudah diaplikasikan, inovatif dan sangat menarik.

3. Media pembelajaran papan Gekola dengan pembelajaran STEM merupakan inovasi pembelajaran yang efektif untuk menghadapi tantangan revolusi industry 4.0 karena meningkatkan efektivitas pembelajaran matematika materi luas bangun datar.

\section{DAFTAR PUSTAKA}

Daryanto. 2012. Media Pembelajaran. Bandung: PT Satu Nusa

Ferdian. 2013. Pengertian, Hakikat dan Teori Belajar dan Pembelajaran. Palangkaraya: Universitas Muhammadiyah Palangkaraya

Hamalik, O. 2007. Proses Belajar Mengajar. Jakarta: Bumi Aksara.

Henriksen, Danah. 2014. "Full STEAM Ahead: Creativity in Excellent STEM Teaching Practices" dalam. The Journal STEAM, 15 (1): 1 - 6

Ismayani, A. 2016. Pengaruh Penerapan STEM Project-Based Learning Terhadap Kreativitas Matematis Siswa SMK. Indonesian Digital Journal of Mathematics and Education 3(4): 264 - 272

Keraf, Yohanes L. 2017. Penggunaan media papan berpaku untuk meningkatkan hasil berlajar matematika. Jurnal Pendidikan Guru Sekolah Dasar 6(8): 824-830 
Kuhn, Mason (2015) "Encouraging Teachers to W.A.I.T Before Engaging Students In Next Generation Science Standards STEAM Activities.," The STEAM Journal: Vol. 2: Iss. 1, Article 15. DOI: 10.5642/steam.20150201.15

Mayasari, Novi dkk. 2017. Pemanfaatan media pembelajaran geoboard dalam pembelajaran matematika materi keliling dan luas bangun segi empat dan segitiga di sd negeri 1 desa temu kecamatan kanor kabupaten bojonegoro tahun 2017. JABDIPAMAS (Jurnal Pengabdian Kepada Masyarakat) 1, no. 1 (2017): 60-65.

Nurhidayati. 2017. Hakikat Media Pembelajaran. http://staffnew.uny.ac.id/upload/132296142/pendidikan/MEDIA+ PEMBELAJARAN.pdf. Diakses, 09 Mei 2018

Onner, Ayse Tugba; Nite, Sandra Bonorden; Capraro, Robert M.; and Capraro, Mary Margaret (2016) "From STEM to STEAM: Students' Beliefs About the Use of Their Creativity," The STEAM Journal: Vol. 2: Iss. 2, Article 6. DOI: 10.5642/steam.20160202.06

Takahashi, Akihiko. 2002. Affordances of computer-based and physical geoboards in problem-solving activities in the middle grades. University of Illinois

Wijaya, A. D., Karmila, N. I. L. A., \& Amalia, M. R. (2015). Implementasi Pembelajaran Berbasis STEAM (Science, Technology, Engineering, Art, Mathematics) pada Kurikulum Indonesia. In Proseding Seminar Nasional Fisika dan Aplikasinya. Tersedia Online: portal. phys. unpad. ac. id. 